\title{
Norwegian Judges' Knowledge of Factors Affecting Eyewitness Testimony: A 12-Year Follow-Up
}

\author{
Ludvig Daae Bjørndal ${ }^{1}$, Lucy McGill², Svein Magnussen ${ }^{1}$, Stéphanie Richardson ${ }^{3}$, Renan \\ Saraiva $^{4}$, Marie Stadel ${ }^{5}$, Tim Brennen ${ }^{1 *}$ \\ ${ }^{1}$ Department of Psychology, University of Oslo, Norway \\ ${ }^{2}$ School of Psychology, Trinity College Dublin, Ireland \\ ${ }^{3}$ School of Psychology and Neuroscience, University of St. Andrews, UK \\ ${ }^{4}$ Department of Psychology, University of Portsmouth \\ ${ }^{5}$ Department of Psychology, University of Groningen, The Netherlands
}

Word count (excl. abstract, acknowledgements, declaration of interests statement, tables and figures): 5898

*Corresponding author. E-mail: t.j.brennen@psykologi.uio.no 


\begin{abstract}
Eyewitness evidence often plays a critical role in decisions made in the criminal justice system. Inaccurate testimonies can, however, impact investigations and potentially lead to miscarriages of justice. To evaluate eyewitness testimonies accurately, judges must be aware of factors that can contaminate this type of evidence. In 2008, a survey of judges in Norway revealed a lack of awareness of several factors that affect eyewitness testimony. However, little is known about judges' current knowledge of this topic and how this knowledge has evolved over time. In the current study, a survey was administered to Norwegian judges $(N=98)$ to evaluate their knowledge of factors that affect eyewitness testimony. Results showed that judges' overall knowledge scores were similar to those reported in 2008, but substantial increases and decreases in knowledge were observed for specific factors. Additional analyses indicated that increased uncertainty regarding some eyewitness factors led to a decline in accuracy when compared to responses observed in 2008. The current study provides an updated assessment of judges' knowledge of eyewitness factors and highlights the need for more comprehensive training for judges regarding factors that can impair eyewitness testimony.
\end{abstract}

Keywords: eyewitness testimony; estimator variables; system variables; survey; judges 


\section{Introduction}

Eyewitness evidence often plays a critical role in decisions made in criminal justice systems. Therefore, inaccurate testimonies can negatively impact investigations and potentially contribute to miscarriages of justice. For instance, data from the Innocence Project (2019) shows that, in the United States, eyewitness misidentification was involved in approximately $70 \%$ of more than 300 wrongful convictions that were overturned using DNA evidence. Although eyewitness evidence is not inherently unreliable (Wixted et al., 2018), it can be contaminated by several factors that affect eyewitness accuracy, such as biased lineup procedures or suggestive interviewing (Toglia et al. 2007). Studies have found that laypeople, judges and legal professionals often show limited knowledge of factors that can contaminate eyewitness evidence (Benton et al., 2006; Desmarais \& Read, 2011; Lindholm, 2008; Wise \& Safer, 2010). In Norway, Magnussen et al. (2008) found that judges were unaware of several important factors that can negatively impact the quality of eyewitness evidence. Since 2000, eyewitness testimony research has grown extensively and has influenced policy guidelines in different countries (National Research Council, 2014; Police and Criminal Evidence Act, 2017; Technical Working Group for Eyewitness Evidence, 2003). However, whether developments in this line of research are reaching decision-makers in legal settings is yet to be examined. A considerable gap in this line of research also relates to whether judges' knowledge of these factors has changed over time. The current study aims to assess Norwegian judges' knowledge of factors that can affect eyewitness testimony, and compare the findings to the knowledge levels reported 12 years ago by Magnussen et al. (2008).

Factors That Influence Eyewitness Testimony: System and Estimator Variables 
There are numerous factors that can negatively impact eyewitness evidence and these are often categorised as estimator or system variables (Wells, 1978). Estimator variables refer to factors that cannot be controlled by the legal system, such as the crime duration, characteristics of the perpetrator or the witnessing conditions. It has been found that judges and legal professionals are not always aware of the detrimental effects of important estimator variables, such as the presence of a weapon (Benton et al., 2006; Houston et al., 2013) and the use of disguises such as a hat (Magnussen et al., 2013; Wise \& Safer, 2004). Knowledge related to the rate of memory loss following an event (often referred to as the "forgetting curve") has also been found to be lacking among judges (Benton et al., 2006). Additionally, an eyewitness's ability to recall minor details about a crime has been erroneously perceived by legal professionals to be a reliable indicator of accurate testimonies (Magnussen et al., 2013; Wise \& Safer, 2004). Knowledge of other estimator variables that has been assessed among legal professionals includes the impact of the eyewitness's attitudes and expectations and the impact of stress on eyewitness memory accuracy (Magnussen et al., 2008; Wise \& Safer, 2004).

System variables refer to factors that can be controlled within the legal system, such as how interviews and lineup identifications are conducted (Wells, 1978). It has been found that judges and legal professionals also have limited knowledge of several system variables that can impair eyewitness accuracy. For example, Jiang and Luo (2016) reported that many legal professionals were unaware of issues related to post-event information which may contaminate witnesses' memory of the event. Furthermore, system variables, such as receiving positive feedback after a lineup identification, can influence witnesses to be mistakenly more confident in their identification at the time of trial (Steblay et al., 2014; Wells \& Bradfield, 1998; Wixted \& Wells, 2017). Inattention to potential sources of confidence inflation is problematic as 
eyewitness confidence can influence decisions regarding the credibility and accuracy of a piece of testimony (Magnussen et al., 2013; Magnussen et al., 2008; Wise et al., 2010). Studies have also found limited knowledge of other important system variables such as bias in the format and presentation of lineup identifications (e.g., Wise \& Safer, 2004). In contrast, higher levels of knowledge among legal professionals have been found regarding the fact that lineup identifications may be biased when witnesses have been exposed to mugshots before seeing the lineup (i.e., mugshot-induced bias; Magnussen et al., 2013; Magnussen et al., 2008; Wise \& Safer, 2010).

\section{Judges' Knowledge of Factors Influencing Eyewitness Testimony}

In 2007, Magnussen et al. (2008) investigated judges' knowledge of eyewitness factors in a sample of Norwegian judges $(N=157)$. The authors adapted a survey developed by Wise and Safer (2004) containing 'True or False' statements about well-established factors that can affect eyewitness testimony (including multiple estimator and system variables). Across all items, the percentage of correct responses in the Norwegian sample ranged from $31 \%$ to $98 \%$, and only five of the 15 statements were answered correctly by at least $80 \%$ of participants. Magnussen et al. (2008) compared their findings to those of Wise and Safer's (2004) sample of judges in the United States $(N=160)$, and found Norwegian judges to be slightly more knowledgeable than US judges, but knowledge profiles were quite similar in the two samples.

Judges' limited awareness of important factors that can contaminate eyewitness evidence is of concern, as judges in many countries have the power to prevent and minimise the negative consequences of erroneous eyewitness testimony (Granhag et al., 2005; Wise \& Safer, 2004). As in many other European countries, Norwegian judges play a critical role in delivering verdicts in most criminal cases. Judges in the Norwegian criminal justice system are employed at 
the level of the District Court ('tingretten'), the Court of Appeal ('lagmannsretten'), or the Supreme Court. Practising judges in Norway include both judges and deputy judges. Deputy judges generally handle less serious criminal court cases, but both positions are central to decision-making in many criminal cases. In criminal trials, the courts are now composed of one to three professional judges and two to five lay judges, with the lay judges always in a majority, following recent reform that abolished the traditional jury system in appeal cases ${ }^{1}$.

As in the United States, the U.K., and other Nordic countries such as Denmark and Sweden, Norway has an adversarial legal system, meaning that judges are less active (e.g., not responsible for collating or preparing evidence) than in the inquisitorial model of certain European countries (Stridbeck \& Granhag, 2010). Furthermore, in the Anglo-Saxon legal system expert witnesses can be called by both parties, whereas these are most commonly appointed by the court in Norway (and in the other Nordic countries; Stridbeck \& Granhag, 2010).

Worldwide, there has been increasing support for the notion that eyewitness evidence can be contaminated and must be assessed via appropriate procedures (e.g., National Research Council, 2014; Technical Working Group for Eyewitness Evidence, 2003). In recent years, discussions related to factors that can affect eyewitness memory and testimonies have been visible in the public sphere and media in Norway (Biørnstad, 2017; Støstad \& Gilberg, 2017), however updated data on legal professionals' awareness of these factors is lacking. Currently, the training in this area for Norwegian judges and deputy judges includes a lecture on eyewitness psychology. Moreover, short courses in witness psychology are available for legal professionals, offered through the Norwegian Bar Association (Juristenes Utdanningssenter, 2019). A 2011 meta-analytic review found a significant increase in knowledge of eyewitness factors among lay

\footnotetext{
${ }^{1}$ Borghan (2017); Regjeringen (2017)
} 
people over time (Desmarais \& Read, 2011). Thus far, no studies have evaluated developments in judges' knowledge levels over time.

The current study assesses the knowledge of factors that may affect the accuracy of eyewitness testimony in a sample of practising Norwegian judges and deputy judges, using the methods and materials adopted by Magnussen et al. (2008). In doing so, this study provides an updated assessment of Norwegian judges' knowledge of eyewitness issues, and investigates how this knowledge has changed in the last 12 years through a comparison with the findings of Magnussen et al. (2008).

\section{Method}

\section{Participants}

The sample comprised 98 practising judges and deputy judges in Norway (52\% female, which is representative of the total population; The Norwegian Courts Administration, n.d.). The mean age of participants was 47.7 years $(S D=11.0)$, indicating that the sample is representative of the population age estimates of judges in Norway $\left(M=55\right.$ years $\left.^{2}\right)$. The mean number of years of experience practising as a judge and/or deputy judge was 9.3 years $(S D=7.5)$. Most participants (78\%) were currently working as trial judges at the level of the District court ('tingretten'), with a smaller proportion of judges (22\%) working at the level of the Court of Appeal ('lagmannsretten'). This is also representative of the population of Norwegian judges with $73 \%$ of Norwegian judges working at the level of the District court and $24 \%$ at the level of the Court of Appeal ${ }^{3}$. With regard to experience prior to becoming a judge, $20 \%$ reported having worked as a prosecutor, $15 \%$ as a defence attorney, $12 \%$ as both a prosecutor and defence

\footnotetext{
${ }^{2}$ Domstoladministrasjon (2019). https://www.domstol.no/innstillingsradet/ledigedommerembeter/soknadsprosessen/8-Vandel---helse---disiplinarreaksjoner---stabilitet-mv/

${ }^{3}$ Domstoladministrasjon (2019). https://www.domstol.no/arsrapport-2019/nokkeltall-2019/\#antallansatte
} 
attorney, and 52\% indicated that they had no previous experience working as a prosecutor and/or defence attorney.

Judges in Norway are required to register with the Norwegian Courts Administration ('Domstoladministrasjonen'). All Norwegian judges, a total of approximately 700 individuals, were invited to participate via an email containing a link to the online survey, distributed by the Norwegian Courts Administration. One reminder email was sent three weeks after the original invitation. Data collection began in June 2019 and ended at the end of August 2019. The study was approved by the Norwegian Centre for Research Data (NSD project number 993725).

\section{Materials}

Participants were asked to complete an online questionnaire that consisted of statements regarding factors that are known to influence eyewitness testimony. This was adapted from Magnussen et al. (2008) and Wise and Safer (2004), who administered surveys composed mostly of items that had received an $80 \%$ agreement rate among memory experts of being reliable enough for a court setting in Kassin et al. (2001). These items describe issues which are frequent in criminal trials (Wise \& Safer, 2004), and have been widely used to evaluate knowledge levels of eyewitness factors among various participant groups (e.g., Desmarais \& Read, 2011; Jiang \& Luo, 2016). Five questions from Magnussen et al. (2008) related to judges' views on how jurors would respond to eyewitness statements were removed to reduce the length of the survey. One item from Magnussen et al. (2008) was not reported in sufficient detail in the original paper to be replicated in the current study. Two additional items on the topics of recovered memories and repression of traumatic memories were adopted from Magnussen and Melinder (2012). Beliefs on the existence of recovered memories have been a matter of great debate (for a review, see Loftus \& Davis, 2006), and repression of memories has been shown to have low agreement rates 
among experts and judges in previous studies (Benton et al., 2006). These items were included to assess Norwegian judges' beliefs which can influence decisions in cases involving claims of repressed memories (Patihis et al., 2014). Therefore, all items used in the current survey were identical to those used by Magnussen et al. (2008), except for the two additional items from Magnussen and Melinder (2012). The questionnaire was developed in this way to enable a direct comparison between responses in the current study and responses in Magnussen et al. (2008). All items were translated and administered in Norwegian. The 15 items evaluating knowledge of eyewitness factors are presented in Table 1.

[Table 1 near here]

\section{Procedure}

Participants were first asked to respond to the eyewitness knowledge questionnaire, consisting of the 15 statements about eyewitness factors that can influence testimony accuracy (e.g., 'A police officer who knows which member of the lineup or photo array is the suspect should not conduct the lineup or photo array'). Similarly to Magnussen et al. (2008), the response format for items 1-6 and 12-15 was 'agree', 'disagree' or 'neither agree nor disagree', while the response format for items 7-11 was 'generally true', 'generally false' or 'don't know'. The knowledge items were presented in the same order as in Table 1 for the entire sample of judges. Participants then responded to a statement that only in exceptional circumstances should a defendant be convicted of a crime solely on the basis of eyewitness testimony (with the response alternatives 'agree', 'disagree' or 'neither agree nor disagree'). Next, participants were asked to respond to the two items adapted from Magnussen and Melinder (2012) related to 
recovered memories and repression of traumatic memories. Participants were subsequently asked to estimate the number of wrongful felony convictions (out of 100) that would have been at least partly influenced by eyewitness error. Following this, participants were asked to report whether they had previously read literature on eyewitness testimony or attended lectures, speeches or seminars on the topic.

Finally, participants were asked to provide demographic information related to their gender, age, years of experience as a judge, whether they work as a trial judge at the District court ('tingretten') or as an appellate judge at the Court of Appeal ('lagmannsretten'), and their experience practising law prior to becoming a judge.

\section{Analysis Plan}

\section{Performance on the Knowledge Scale and Comparison with 2008}

Similar to Magnussen et al. (2008), answers to the 15 eyewitness knowledge items were coded as either correct (coded as 1) or incorrect (coded as 0; including incorrect, 'neither' and 'don't know' responses), and a mean number of correct responses was calculated for the 15-item knowledge scale. Descriptive statistics were computed to examine the percentage of correct responses for each statement, and Pearson's chi-squared tests were conducted to compare the accuracy of judges' responses in the current study with the responses obtained by Magnussen et al. (2008). In addition, an exploratory analysis using Pearson's chi-squared tests was run on the three types of responses judges could choose from (namely 'agree', 'disagree', or 'neither' for items 1-6 and 12-15; or 'generally true', 'generally false' or 'don't know' for items 7-11) in order to assess whether response choices differed from 2008 in other ways than in terms of accuracy. Alpha levels were set at .05 and Cramér's $V$ was used as a measure of effect size. The 
Benjamini-Hochberg correction was applied to all p-values to account for multiple testing and false discovery rates (Benjamini \& Hochberg, 1995).

Correlates of Judges' Knowledge

A point-biserial correlation coefficient was calculated to examine the association between judges' knowledge and whether they believed in convicting a defendant solely on the basis of eyewitness testimony. Pearson correlation coefficients were computed to examine the relationship between the 15-item eyewitness knowledge scale score and the estimation of wrongful convictions due to eyewitness error, as well as with the number of years practising law. T-tests were used to compare the knowledge scores of judges who had previously been exposed to information about eyewitness testimony and those who had not. Finally, ANOVAs were used to assess whether knowledge scores differed between groups with different legal backgrounds. All analyses were conducted using the statistical software R (R Core Team, 2018).

\section{Results}

\section{Performance on the Knowledge Scale}

Table 2 presents the main descriptive statistics for the 15 eyewitness factor knowledge items, including the responses reported by Magnussen et al. (2008). In the current sample, accurate responses ranged from $22 \%$ to $98 \%$ with a mean accuracy of $67 \%$ across all items. The mean score on the 15-item knowledge scale was $10.08(S D=2.25)$ out of 15 . Six of the 15 items were answered correctly by at least $80 \%$ of respondents (items $3,4,5,7,9$ and 14). The impact of attitudes and expectations, post-event information and confidence malleability on eyewitness testimonies were all known by the vast majority of judges ( $98 \%, 97 \%$ and $92 \%$ respectively). In contrast, only a small percentage of judges were aware of the effects of a hat and of the forgetting curve ( $31 \%$ and $34 \%$ respectively). 
[Table 2 near here]

\section{Comparing Norwegian Judges' Knowledge in the 2008 and 2019 Samples}

In the current survey, the mean proportion of correct responses was $67 \%$, compared to $63 \%$ in the 2008 sample, $\chi^{2}(1)=0.32, p=.57, V=0.04$. The results for the chi-squared tests comparing accuracy scores for each eyewitness knowledge item in the 2008 and 2019 samples are reported in Table 3. Five items (items 2, 6, 13, 14 and 15) showed significant increases in accuracy in the 2019 sample when compared to the 2008 sample. Disagreement with the statement that a witness's ability to recall minor details about a crime is a good indicator of a reliable testimony (item 2) increased by $16 \%$. Disagreement with the statement that an eyewitness's confidence at trial is a good predictor of accuracy in identifying the defendant as the perpetrator (item 6) increased by $47 \%$. Furthermore, a 30\% increase in disagreement with the statement that attorneys know how most eyewitness factors affect eyewitness accuracy (item 13) was observed. Disagreement with the statement that jurors know how most eyewitness factors affect eyewitness accuracy (item 14) increased by $12 \%$, and disagreement with the notion that jurors can distinguish between accurate and inaccurate eyewitnesses (item 15) increased by $22 \%$.

Four items (items 1, 8, 10 and 11) showed significant decreases in accuracy compared to the 2008 sample. Agreement with the statement that it is harder for a witness of a crime to recognise a perpetrator who is wearing a hat than one that is not (item 1) decreased by $24 \%$. Agreement with the statement that the presence of a weapon can impair an eyewitness's ability to accurately identify a perpetrator's face (item 8) decreased by $16 \%$. Agreement with the statement that the rate of memory loss is greatest right after the event (item 11) decreased by 
17\%. Furthermore, agreement with the statement that sequential lineups produce fewer misidentifications than simultaneous lineups (item 10) decreased by $16 \%$.

[Table 3 near here]

Responses for six items did not appear to differ greatly from the responses observed in Magnussen et al. (2008). The same proportion of accurate responses was observed for the statement that an eyewitness's perception of an event is influenced by their attitudes and expectations (item 3), and for the statement that being exposed to mugshots biases the witness towards a suspect (item 9). No differences between the 2008 and 2019 samples were observed for the statement that a policeman should not know whether or not the suspect is in the lineup (item 4), for the statement that post-event information affects an eyewitness's testimony (item 5), and for the statement that very high stress at the time of observation has a negative impact on the accuracy of eyewitness testimony (item 12). Correct answers to the statement that an eyewitness's confidence can be influenced by factors that are unrelated to identification accuracy (item 7) increased by $7 \%$ in the 2019 sample, but this difference was not statistically significant. Exploratory Analyses of Response Patterns

For the main analysis, knowledge scores were evaluated by contrasting accurate responses (e.g., 'agree') against the two inaccurate alternatives (e.g., 'disagree' and 'don't know'), in line with the procedure used by Magnussen et al. (2008). A further exploratory analysis was conducted using Pearson's chi-squared tests in a 3 (answer choice: e.g., 'agree', 'disagree' and 'don't know') by 2 (sample: 2008 vs. 2019) model. This analysis focused on examining standardised residuals to elucidate which of the three answer choices showed greater 
changes between 2008 and 2019 (Sharpe, 2015). The main rationale for this analysis was to better examine whether changes in performance across the 2008 and 2019 samples were due to changes in opinion (i.e., 'agree' vs. 'disagree' responses), or shifts to 'don't know' responses from either 'agree' or 'disagree' responses.

Analyses of the residuals of the significant chi-squared tests showed that for three items (confidence-accuracy, attorneys' knowledge, and jurors distinguishing eyewitnesses), the improvement in accuracy occurred due to a decrease in both inaccurate responses and 'neither' responses (see Figure 1). Regarding the knowledge improvement in item 2 (minor details), the increase in accuracy occurs almost exclusively due to fewer inaccurate responses, with little change in 'neither' responses. In contrast, items that showed a decline in accuracy (effects of a hat, weapon focus, lineup presentation format and forgetting curve) presented an increase in 'neither'/'don't know' responses, with little changes in inaccurate responses. For item 1 (the effects of a hat), for example, a significant change compared to 2008 was observed, $\chi^{2}(2)=$ $14.87, p<.001, V=0.24$, and this change was accounted for by a decrease in correct responses (55\% in 2008 versus $31 \%$ in 2019) and an increase in 'neither' responses ( $34 \%$ in 2008 versus $55 \%$ in 2019). Therefore, for item 1, there was a negligible change of $3 \%$ in the proportion of judges that provided an inaccurate response (i.e., 'disagree').

[Figure 1 near here]

\section{Correlates of Judges' Knowledge}

Additionally, the relationships between judges' knowledge and several other variables were examined. Judges were heterogeneous in their responses to the item that only in exceptional 
circumstances should a person be convicted solely on the basis of eyewitness testimony $(27.6 \%$ 'agree', 36.7\% 'neither agree nor disagree' and 35.7\% 'disagree'). The average estimate of the number of wrongful convictions (out of 100) at least partly influenced by eyewitness error was $56.71(S D=30.1)$. The majority of judges reported having previously read literature on eyewitness testimony ( $70.4 \%$ 'yes', $21.4 \%$ 'no', $8.2 \%$ 'don't know or can't remember'). Similarly, the majority of participants reported having attended lectures, speeches or seminars on the topic ( $89.8 \%$ 'yes', $7.1 \%$ 'no', 3.1\% 'don't know or can't remember').

Pearson correlations and point-biserial correlations revealed non-significant relationships between judges' knowledge scores and three other variables: i) the belief that only in exceptional circumstances should a person be convicted solely on the basis of eyewitness testimony, $r(60)=$ $0.15, p=.26$; ii) participants' estimates for the number of wrongful convictions (out of 100) that are at least partly influenced by eyewitness error, $r(96)=0.15, p=.14$; and iii) years of experience practising as a judge and/or deputy judge, $r(96)=-0.12, p=.22$. A between-subjects $t$-test revealed no significant differences in knowledge scores between judges who had read literature about eyewitness factors $(M=10.2, S D=2.2)$ and those who had not $(M=9.5, S D=$ $2.5), t(30)=1.16, p=.26$. Most judges $(90 \%)$ reported having attended a seminar about eyewitness testimony, therefore it was not feasible to conduct comparisons with this variable. Additionally, a one-way ANOVA revealed no effect of previous type of legal experience (e.g., prosecutor, defence attorney) on knowledge scores, $F(3,94)=0.47, p=.70, \eta^{2}=0.01$.

\section{Additional Items}

Finally, responses for the two additional items concerning recovered memories and traumatic memories were examined. The first item evaluated judges' beliefs about recovered memories in psychotherapy. No judges reported that they believed all recovered memories in 
psychotherapy about traumatic events from childhood are real, 28\% reported that most are real, $20 \%$ reported that most are false, $1 \%$ reported that are all false, and $51 \%$ responded that they did not know. The second item evaluated judges' beliefs related to the repression of adult traumatic memories. Most judges (43\%) responded that a perpetrator who has committed murder and claims they have no memory of the crime is lying, 37\% responded that they did not know, and $20 \%$ responded that they believed that the perpetrator is telling the truth.

\section{Discussion}

The current study provides an updated assessment of Norwegian judges' knowledge of factors that can affect eyewitness testimony, and compares the results with the findings of Magnussen et al. (2008). The overall accuracy observed for the 15-item knowledge scale in the current sample (67\%) was comparable to the overall accuracy observed in $2008(63 \%)$.

However, substantial increases and decreases in judges' knowledge were observed for specific items representing factors that can affect the accuracy of eyewitness testimonies.

One of the most notable differences in judges' knowledge was observed for the item stating that confidence is not necessarily a reliable indicator of testimony accuracy. Participants' performance in the current survey ( $78 \%$ accuracy) showed an increase for this item not only when compared to previous performance in Norway (31\%; Magnussen et al., 2008), but also in comparison to judges' accuracy in the United States (32\%; Wise \& Safer, 2004), and to a similar item administered to judges in China (42\%; Jiang \& Luo, 2016). It is also worth noting that judges' knowledge in the current sample with regard to the eyewitness confidence-accuracy relationship is comparable to that observed among experts in eyewitness psychology (Benton et al., 2006). There has been extensive research on the eyewitness confidence-accuracy relationship in recent years, enhancing the understanding of factors that can inflate eyewitness confidence 
(e.g., Palmer et al., 2013; Wixted \& Wells, 2017). These recent developments may have contributed to increased awareness of issues concerning eyewitness confidence inflation, as reflected by an increase in correct responses regarding the diagnostic value of confidence at the time of trial. A recent review and synthesis of the existing research found that there is a strong relationship between confidence and accuracy, but that this relationship is dependent upon the quality of the identification procedures (e.g., lineup fairness; Wixted \& Wells, 2017). Therefore, one important caveat is that the supposed correct answer to the confidence-accuracy relationship item is somewhat unclear, given that the item did not elaborate on the identification procedure conditions (and high confidence can be a reliable indicator of testimony accuracy, as long as it is an early statement of confidence and adequate identification procedures are followed),

Additionally, judges were less likely to believe that jurors have adequate knowledge of factors affecting eyewitness testimony and that jurors can accurately distinguish accurate from inaccurate eyewitness testimonies, compared to Magnussen et al. (2008). These findings indicate that scepticism towards jurors' and attorneys' knowledge of these topics has increased among Norwegian judges since 2008. These results are interesting in light of the recent abolition of juries in the Norwegian criminal justice system, described above.

Significant decreases in correct responses were observed for four items, including the statements referring to the effects of a hat and the presence of a weapon. These items refer to effects that have been extensively researched in the eyewitness psychology literature and have been found to negatively affect eyewitness identifications (e.g., Fahsing et al., 2004; Fawcett et al., 2013; Mansour et al., 2012), thus the current findings highlight a discrepancy between the literature and the knowledge of judges in Norway. Similar surveys have also found that judges 
provide few correct responses to items concerning both the effects of a hat (e.g., Wise \& Safer, 2004) and the presence of a weapon (e.g., Houston et al., 2013) on eyewitness testimony.

Significant declines in knowledge were observed for an additional two items, namely the items related to the forgetting curve and the lineup presentation format. Other evaluations of judges' knowledge of the forgetting curve have yielded mixed results (Granhag et al., 2005; Jiang \& Luo, 2016; Wise \& Safer, 2004). A lack of knowledge among judges for the lineup presentation item has been found elsewhere (Jiang \& Luo, 2016; Wise \& Safer, 2004). However, the supposed correct answer for the lineup presentation format statement is somewhat less clear. Recent research has found that identifications from sequential lineups may be more diagnostic of guilt, but may also lead to witnesses being more conservative, that is, less likely to identify culprits (and less likely to make any selection at all) from a sequential lineup (Steblay et al., 2011; Valentine \& Fitzgerald, 2016). So although there seems to be a consensus that simultaneous lineups produce more misidentifications in target-absent lineups, there is still a lack of consensus as to the most appropriate procedure, given that sequential lineups tend to produce fewer misidentifications, but also fewer accurate identifications.

With regard to the four items for which a decline in knowledge was observed, a close inspection of the data revealed a substantial increase in the 'don't know' or 'neither' responses, when compared to the 2008 sample. This finding suggests that the decrease in knowledge of well-established factors that affect eyewitness testimony is partly reflected by increased uncertainty about these factors. There are a number of potential reasons for this finding. Notably, judges could have a non-specific awareness that various circumstantial factors contribute to eyewitness reliability, or an over-reliance on anecdotal cases, both of which have been shown to hinder one's ability to apply knowledge objectively (Papailiou et al., 2015; Tversky \& 
Kahneman, 1973). Further research investigating the way in which judges justify their answer choices could provide empirical insights into the response patterns observed. In contrast, increases in knowledge appeared to be matched with a decrease in 'don't know' or 'neither' responses and inaccurate responses.

It is worth noting that six items produced very similar responses to those described by Magnussen et al. (2008), namely, the items concerning post-event information, conducting lineups, mugshot-induced bias, attitudes and expectations, the impact of stress and confidence malleability. For all six of these items the proportion of correct responses was high in both the current sample and the 2008 sample (from 70\% to 98\%; Magnussen et al., 2008). High accuracy among judges for many of these items has also been reported in other studies, such as for the impact of stress (Benton et al., 2006) and post-event information (Benton et al., 2006; Wise \& Safer, 2004). Regarding the impact of stress, it is important to note that although the findings that very high stress negatively affects eyewitness memory still seem to hold true in some cases (Deffenbacher et al., 2004), this is a research field which typically produces mixed results, with some studies finding no association between stress and eyewitness performance (Sauerland et al., 2016).

Norwegian judges in the current sample appear to have better knowledge of the potential impact of system variables as opposed to estimator variables on the accuracy of eyewitness testimony. This is of interest as enhanced knowledge of system factors can lead to the development of more adequate procedures and policies when dealing with eyewitness evidence. However, a lack of awareness of estimator variables is of concern as it may indicate that judges may not be sufficiently considering important factors that can impair eyewitness evidence (e.g., presence of a weapon or the effects of a hat). Other studies have also found higher knowledge of 
system variables among judges and law enforcement personnel (Benton et al., 2006), as well as among jurors and laypeople (Benton et al., 2006; Desmarais \& Read, 2011). Desmarais and Read (2011) argue that system variables are more concrete and therefore may be easier to understand, which could be one potential explanation for this finding.

For the item evaluating beliefs about recovered memories during psychotherapy, the proportion of responses deemed the most correct was slightly lower when compared with the responses of a sample of Norwegian psychologists and psychiatrists, all of whom had previously served as expert witnesses in court (Melinder \& Magnussen, 2015). For the item evaluating beliefs about the repression of adult traumatic memories in perpetrators of murder, a slightly higher proportion of the current sample responded that the perpetrator is lying when compared with the Norwegian psychologists and psychiatrists that had served as expert witnesses. Although the debate concerning repressed memories continues (see Brewin \& Andrews, 2014; McNally, 2017; Otgaar et al., 2019; Patihis et al., 2014), a recent survey found that most memory experts considered it implausible that traumatic memories are often repressed, and also disagreed that repressed memories can accurately be retrieved in therapy (Patihis, Ho, Loftus, \& Herrera, 2018). The findings of the current study suggest that these topics are not widely known by judges in Norway-

The current study provides an updated assessment of Norwegian judges' knowledge of factors affecting eyewitness evidence in 2019. Although it is difficult to make direct comparisons with other studies due to variations in items and response options across studies, these findings are generally consistent with similar surveys assessing legal professionals' knowledge of eyewitness factors in several countries, many of which, like Norway, also have an adversarial system. Houston et al. (2013), for example, found exactly the same mean of correct responses 
(67\%) among Scottish judges. Wise and Safer (2004) found the mean percentage of correct responses to be $55 \%$ for judges in the U.S., using a similar 14 -item knowledge scale. Jiang and Luo (2016) assessed 216 judges in China and found that the mean number of correct responses was $58 \%$.

Similarly to Magnussen et al. (2008), no significant relationships were observed between the knowledge of eyewitness factors and correlates such as the type of legal experience that judges had, the number of years they had been practising, and their exposure to eyewitness testimony literature. Currently, the training for Norwegian deputy judges and judges includes a lecture (two and three hours in length, respectively) on eyewitness psychology, which covers basic cognitive phenomena, research on eyewitness testimony, false confessions, and their relation to known legal cases. However, given the importance of judges as triers of fact in the legal system and the potentially detrimental consequences of eyewitness error in the courtroom, the current results support a call for comprehensive education and training in eyewitness research for judges (Kovera \& McAuliff, 2000; Magnussen et al., 2008; Wise et al., 2014), and may serve as a useful indication of knowledge gaps to be considered in future training.

\section{Limitations}

The current study has some limitations. Firstly, the literature has shown that multiplechoice type surveys may not reflect actual knowledge application during trials, given the lack of contextual and case-specific details that would be present in a trial setting (Houston et al., 2013). The authors of the present study reasoned that using multiple-choice questions would be beneficial for increasing response rate. Secondly, the current survey did not include an exhaustive list of factors that can affect eyewitness testimony, however factors that were included had extensive empirical support and frequently appear in other surveys examining 
knowledge of eyewitness psychology (e.g., Kassin et al., 2001). Finally, 'generally true' was always the correct response to the five items with response options: 'generally true', 'generally false' or 'don't know'. Therefore, it is possible that knowledge scores for these items were affected by acquiescence bias (Podsakoff et al., 2012), which could be corrected by phrasing the items so that the correct responses are represented by different response options.

\section{Conclusion}

In conclusion, the current study offers an updated assessment of Norwegian judges' knowledge of factors affecting eyewitness testimony, as well as a comparison with the results of Magnussen et al. (2008). Overall, judges in Norway appear to have a relatively high level of knowledge of several factors that may affect eyewitness testimony, but a low level of knowledge was still observed for several relevant variables. Lack of knowledge of some eyewitness factors is of concern given that judges are central to decision-making in the Norwegian criminal justice system. When compared to the 2008 sample, both increases and decreases in knowledge were observed for items evaluating various eyewitness factors. The findings of the current study indicate, as suggested by Magnussen et al. (2008), that comprehensive educational programmes for judges and other legal professionals should be implemented to further increase awareness of factors that can affect eyewitness testimonies and cope with eyewitness error. Furthermore, future research may seek to provide an evaluation of the existing training that has been implemented for deputy judges in Norway in recent years. 


\section{Acknowledgements}

We are grateful to the participants for their time and for the feedback given. We would also like to acknowledge the Norwegian Courts Administration (Domstoladministrasjonen) for kindly agreeing to circulate our survey among Norwegian judges. This work was supported by the Junior Researcher Programme (JRP), an international initiative to support early-career researchers in psychology.

\section{Declaration of interest statement}

The authors of the current study have no potential conflicts of interest to report. 


\section{References}

Benjamini, Y., \& Hochberg, Y. (1995). Controlling the false discovery rate: A practical and powerful approach to multiple testing. Journal of the Royal Statistical Society: Series B (Methodological), 57(1), 289-300.

Benton, T. R., Ross, D. F., Bradshaw, E., Thomas, W. N., \& Bradshaw, G. S. (2006). Eyewitness memory is still not common sense: Comparing jurors, judges and law enforcement to eyewitness experts. Applied Cognitive Psychology, 20(1), 115-129. doi:10.1002/acp.1171

Biørnstad, L. (2017, August 01). De problematiske øyenvitnene: Hva så du egentlig? [The problematic eyewitnesses: What did you really see?].forskning.no. Retrieved from https://forskning.no/hjernen-kriminalitet/de-problematiske-oyenvitnene-hva-sa-duegentlig/331541

Brewin, C. R., \& Andrews, B. (2014). Why it is scientifically respectable to believe in repression: A response to Patihis, Ho, Tingen, Lilienfield, and Loftus (2014). Psychological Science, 25(10), 1964-1966. https://doi.org/10.1177/0956797614541856

Deffenbacher, K. A., Bornstein, B. H., Penrod, S. D., \& McGorty, E. K. (2004). A metaanalytic review of the effects of high stress on eyewitness memory. Law and Human Behaviour, 28(6), 687-706. doi: 10.1007/s10979-004-0565-x

Desmarais, S. L., \& Read, J. D. (2011). After 30 years, what do we know about what jurors know? A meta-analytic review of lay knowledge regarding eyewitness factors. Law and Human Behavior, 35(3), 200-210. doi:10.1007/s10979-010-9232-6 
Fahsing, I. A., Ask, K., \& Granhag, P. A. (2004). The man behind the mask: Accuracy and predictors of eyewitness offender descriptions. Journal of Applied Psychology, 89(4), 722-729. doi:10.1037/0021-9010.89.4.722

Fawcett, J. M., Russell, E. J., Peace, K. A., \& Christie, J. (2013). Of guns and geese: A meta-analytic review of the 'weapon focus' literature. Psychology, Crime \& Law, 19(1), 35-66. https://doi.org/10.1080/1068316X.2011.599325

Granhag, P. A., Strömwall, L. A., \& Hartwig, M. (2005). Eyewitness testimony: Tracing the beliefs of Swedish legal professionals. Behavioral Sciences and the Law, 23(5), 709727. doi:10.1002/bsl.670

Houston, K. A., Hope, L., Memon, A., \& Read, J. D. (2013). Expert testimony on eyewitness evidence: In search of common sense. Behavioral Sciences and the Law, 31(5), 637-651. doi:10.1002/bsl.2080

The Innocence Project (2019, August 8). Eyewitness Identification Reform. Retrieved from https://www.innocenceproject.org/eyewitness-identification-reform/

Jiang, L., \& Luo, D. (2016). Legal professionals' knowledge of eyewitness testimony in China: A cross-sectional survey. PLoS ONE, 11(2), 1-8. doi:10.1371/journal.pone. 0148116

Juristenes Utdanningssenter (2019, September 5). Vitnepsykologi. [Witness psychology]. Retrieved from https://www.jus.no/kurs-og-opplaering/vitnepsykologi/\#Hva_laerer_du 
Kassin, S. M., Tubb, V. A., Hosch, H. M., \& Memon, A. (2001). On the "general acceptance" of eyewitness testimony research: A new survey of the experts. American Psychologist, 56(5), 405-416. doi:10.1037//0003-066X.56.5.405

Kovera, M. B., \& McAuliff, B. D. (2000). The effects of peer review and evidence quality on judge evaluations of psychological science: Are judges effective gatekeepers? Journal of Applied Psychology, 85(4), 574-586. doi:10.1037//0021-9010.85.4.574

Lindholm, T. (2008). Who can judge the accuracy of eyewitness statements? A comparison of professionals and lay-persons. Applied Cognitive Psychology, 22(9), 1301-1314. doi:10.1002/acp.1439

Loftus, E. F., \& Davis, D. (2006). Recovered memories. Annual Review of Clinical Psychology, 2, 469-498. doi: 10.1146/annurev.clinpsy.2.022305.095315

Magnussen, S., Safer, M. A., Sartori, G., \& Wise, R. A. (2013). What Italian defense attorneys know about factors affecting eyewitness accuracy: A comparison with U.S. and Norwegian samples. Frontiers in Psychiatry, 4, 1-6. doi:10.3389/fpsyt.2013.00028

Magnussen, S., Wise, R. A., Raja, A. Q., Safer, M. A., Pawlenko, N., \& Stridbeck, U. (2008). What judges know about eyewitness testimony: A comparison of Norwegian and US judges. Psychology, Crime \& Law, 14(3), 177-188. https://doi.org/10.1080/10683160701580099

Mansour, J. K., Beaudry, J. L., Bertrand, M. I., Kalmet, N., Melsom, E. I., \& Lindsay, R. C. L. (2012). Impact of disguise on identification decisions and confidence with 
simultaneous and sequential line-ups. Law and Human Behavior, 36(6), 513-526. doi:10.1037/h0093937

McNally, R. J. (2017). False memories in the laboratory and in life: Commentary on Brewin and Andrews (2016). Applied Cognitive Psychology, 31(1), 40-41. doi:10.1002/acp.3268

Melinder, A., \& Magnussen, S. (2015). Psychologists and psychiatrists serving as expert witnesses in court: what do they know about eyewitness memory? Psychology, Crime \& Law, 21(1), 53-61. http://dx.doi.org/10.1080/1068316X.2014.915324

National Research Council. (2014). Identifying the culprit: Assessing eyewitness identification. National Academies Press.

Otgaar, H., Howe, M. L., Patihis, L., Merckelbach, H., Lynn, S. J., Lilienfield, S. O., \& Loftus, E. F. (2019). The return of the repressed: The persistent and problematic claims of long-forgotten trauma. Perspectives on Psychological Science. https://doi.org/10.1177/1745691619862306

Palmer, M. A., Brewer, N., Weber, N., \& Nagesh, A. (2013). The confidence-accuracy relationship for eyewitness identification decisions: Effects of exposure duration, retention interval, and divided attention. Journal of Experimental Psychology: Applied, 19(1), 55-71. doi:10.1037/a0031602

Papailiou, A. P., Yokum, D. V., \& Robertson, C. T. (2015). The novel New Jersey eyewitness instruction induces skepticism but not sensitivity. PLoS ONE, 10(12), 1-16. https://doi.org/10.1371/journal.pone.0142695 
Patihis, L., Ho, L. Y., Loftus, E. F., \& Herrera, M. E. (2018). Memory experts' beliefs about repressed memory. Memory, 1-6. https://doi.org/10.1080/09658211.2018.1532521

Patihis, L., Ho, L. Y., Tingen, I. W., Lilienfeld, S. O., \& Loftus, E. F. (2014). Are the "memory wars" over? A scientist-practitioner gap in beliefs about repressed memory. Psychological Science, 25(2), 519-530. doi:10.1177/0956797613510718

Podsakoff, P. M., MacKenzie, S. B., \& Podsakoff, N. P. (2012). Sources of method bias in social science research and recommendations on how to control it. Annual Review of Psychology, 63, 539-569. doi: 10.1146/annurev-psych-120710-100452

Police and Criminal Evidence Act (2017). Code of Practice for the identification of persons by Police Officers. TSO: Norwich, UK.

R Core Team (2018). R: A language and environment for statistical computing. $R$ Foundation for Statistical Computing, Vienna. Austria. URL: https://www.Rproject.org/

Sauerland, M., Raymaekers, L. H., Otgaar, H., Memon, A., Waltjen, T. T., Nivo, M., ... \& Smeets, T. (2016). Stress, stress-induced cortisol responses and eyewitness identification performance. Behavioral Sciences \& the Law, 34(4), 580-594. doi: $10.1002 / b s 1.2249$

Sharpe, D. (2015). Your chi-square test is statistically significant: Now what? Practical Assessment, Research and Evaluation, 20(8), 1-10. Retrieved from https://pareonline.net/getvn.asp? $v=20 \& n=8$ 
Steblay, N. K., Dysart, J. E., \& Wells, G. L. (2011). Seventy-two tests of the sequential lineup superiority effect: A meta-analysis and policy discussion. Psychology, Public Policy, and Law, 17(1), 99-139. doi:10.1037/a0021650

Steblay, N. K., Wells, G. L., \& Douglass, A. B. (2014). The eyewitness post identification feedback effect 15 years later: Theoretical and policy implications. Psychology, Public Policy, and Law, 20(1), 1-18. doi:10.1037/law0000001

Stinson, V., Devenport, J. L., Cutler, B. L., \& Kravitz, D. A. (1997). How effective is the motion-to-suppress safeguard? Judges' perceptions of the suggestiveness and fairness of biased lineup procedures. Journal of Applied Psychology, 82(2), 211-220. http://dx.doi.org/10.1037/0021-9010.82.2.211

Stridbeck, U., \& Granhag, P.A. (2010). Legal procedures in the Nordic countries and in the USA: a comparative overview. In: Granhag, P. A. (ed), Forensic psychology in context. Nordic and international approaches (pp. 14-32). Devon: Willan Publishing.

Støstad, M. N., \& Gilberg, L. B. (2017, June 10). Jeg har et falskt minne. Det har antagelig du også. [I have a false memory. Probably so do you]. NRK. Retrieved from https://www.nrk.no/dokumentar/xl/den-forraederske-hukommelsen-1.13512390

Technical Working Group for Eyewitness Evidence. (2003). Eyewitness evidence: A trainer's manual for law enforcement. Washington, DC: National Institute of Justice.

Toglia, M. P., Read, J. D., Ross, D. F., \& Lindsay, R. C. L. (2007). The handbook of eyewitness psychology: Volume I: Memory for events. Psychology Press. 
Tversky, A., \& Kahneman, D. (1973). Availability: A heuristic for judging frequency and probability. Cognitive Psychology, 5(2), 207-232. https://doi.org/10.1016/00100285(73)90033-9

Valentine, T., \& Fitzgerald, R. J. (2016). Identifying the culprit: An international perspective on the National Academy of Sciences report on eyewitness identification evidence. Applied Cognitive Psychology, 30(1), 135-138. doi:10.1002/acp.3164

Wells, G. L. (1978). Applied eyewitness-testimony research: System variables and estimator variables. Journal of Personality and Social Psychology, 36(12), 1546-1557.

Wells, G. L., \& Bradfield, A. L. (1998). “Good, you identified the suspect”: Feedback to eyewitnesses distorts their reports of the witnessing experience. Journal of Applied Psychology, 83(3), 360-376.

Wise, R. A., Gong, X., Safer, M. A., \& Lee, Y. T. (2010). A comparison of Chinese Judges' and US judges' knowledge and beliefs about eyewitness testimony. Psychology, Crime \& Law, 16(8), 695-713. https://doi.org/10.1080/10683160903153893

Wise, R. A., \& Safer, M. A. (2004). What US judges know and believe about eyewitness testimony. Applied Cognitive Psychology, 18(4), 427-443. doi:10.1002/acp.993

Wise, R. A., \& Safer, M. A. (2010). A comparison of what U.S. judges and students know and believe about eyewitness testimony. Journal of Applied Social Psychology, 40(6), 1400-1422. https://doi.org/10.1111/j.1559-1816.2010.00623.x 
Wise, R. A., Sartori, G., Magnussen, S., \& Safer, M. A. (2014). An examination of the causes and solutions to eyewitness error. Frontiers in Psychiatry, 5, 1-8. doi:10.3389/fpsyt.2014.00102

Wixted, J. T., Mickes, L., \& Fisher, R. P. (2018). Rethinking the reliability of eyewitness memory. Perspectives on Psychological Science, 13(3), 324-335. doi: $10.1177 / 1745691617734878$

Wixted, J. T., \& Wells, G. L. (2017). The relationship between eyewitness confidence and identification accuracy: A new synthesis. Psychological Science in the Public Interest, 18(1), 10-65. doi:10.1177/1529100616686966 


\section{Footnotes}

Borghan, A. (2017, October 13). Juryordningen avskaffes over nyttår. [The jury system will be abolished after New Year]. NRK. Retrieved from https://www.nrk.no/norge/juryordningen-avskaffes-over-nyttar-1.13732218

Domstoladministrasjonen [Norwegian Courts Administration] (2019).

https://www.domstol.no/innstillingsradet/ledige-dommerembeter/soknadsprosessen/8$\underline{\text { Vandel---helse---disiplinarreaksjoner---stabilitet-mv/ }}$

The Norwegian Courts Administration. (n.d.). Nøkkeltall 2019. [Key figures 2019]. Retrieved from https:/www.domstol.no/arsrapport-2019/nokkeltall2019/\#antallansatte

Domstoladministrasjon [Norwegian Courts Administration] (2019). https://www.domstol.no/arsrapport-2019/nokkeltall-2019/\#antallansatte

Regjeringen. (2017, June 16). Oppheving av juryordningen. [Repealing the jury system]. Retrieved from https://www.regjeringen.no/no/aktuelt/oppheving-avjuryordningen/id2557578/ 


\section{Tables With Captions}

Table 1.

English Versions of the 15 Items Composing the Eyewitness Knowledge Scale

\begin{tabular}{|c|c|c|}
\hline Topics & Statements & Response Format \\
\hline $\begin{array}{l}\text { 1. Effects of a } \\
\text { hat }\end{array}$ & $\begin{array}{l}\text { It is significantly harder for a witness of a crime to } \\
\text { recognise a perpetrator who is wearing a hat during the } \\
\text { commission of a crime than a perpetrator who is not } \\
\text { wearing a hat. }\end{array}$ & Agree*/Neither/Disagree \\
\hline
\end{tabular}

2. Minor details A witness's ability to recall minor details about a crime is a Agree/Neither/Disagree* good indicator of the accuracy of the witness's

identification of the perpetrator of the crime.

3. Attitudes and expectations

4. Conducting lineups

5. Effects of post-event information

6. Confidenceaccuracy

7. Confidence malleability

8. Weapon focus

9. Mugshotinduced bias

10. Lineup presentation format

11. Forgetting curve
An eyewitness's perception and memory for an event may be affected by his or her attitudes and expectations.

A police officer who knows which member of the lineup or photo array is the suspect should not conduct the lineup or photo array.

Eyewitness testimony about an event often reflects not only what a witness actually saw but information obtained later on from other witnesses, the police, the media etc.

An eyewitness's confidence is a good predictor of his or her accuracy in identifying the defendant as the perpetrator of the crime.

An eyewitness's confidence can be influenced by factors that are unrelated to identification accuracy.

The presence of a weapon can impair an eyewitness's ability to accurately identify the perpetrator's face.

Exposure to mugshots of a suspect increases the likelihood that the witness will later choose that suspect from a lineup.

Witnesses are more likely to misidentify someone in a culprit-absent lineup when it is presented in a simultaneous (members of a lineup are present at the same time) as opposed to a sequential procedure (members of a lineup are presented individually).

The rate of memory loss for an event is greatest right after the event and then levels off over time.
Agree*/Neither/Disagree

Agree*/Neither/Disagree

Agree*/Neither/Disagree

Agree/Neither/Disagree*

Generally true*/Generally false/Don't know

Generally true*/Generally false/Don't know

Generally true*/Generally false/Don't know

Generally true*/Generally false/Don't know

Generally true*/Generally false/I don't know 
12. Impact of stress

13. Attorneys' knowledge

14. Jurors' knowledge

15. Jurors distinguish eyewitnesses
Very high stress at the time of the observation has a negative effect on the accuracy of testimony.

Attorneys know how most eyewitness factors affect eyewitness accuracy.

Jurors know how most eyewitness factors affect eyewitness accuracy.

Jurors can distinguish between accurate and inaccurate eyewitnesses.
Agree*/Neither/Disagree

Agree/Neither/Disagree*

Agree/Neither/Disagree* Agree/Neither/Disagree*

Note. *Indicates the response alternative believed to be most correct according to current research in legal and witness psychology 
Table 2 .

Distribution of Judges' Responses to Eyewitness Statements in 2008 and 2019.

\begin{tabular}{|c|c|c|c|c|c|c|}
\hline Topics & 2019 & 2008 & 2019 & 2008 & 2019 & 2008 \\
\hline & \multicolumn{2}{|c|}{ Agree $\%$} & \multicolumn{2}{|c|}{ Neither $\%$} & \multicolumn{2}{|c|}{ Disagree $\%$} \\
\hline 1. Effects of a hat & $31 *$ & 55 & 55 & 34 & 14 & 11 \\
\hline 2. Minor details & 11 & 30 & 42 & 40 & $47^{*}$ & 31 \\
\hline 3. Attitudes and expectations & $98 *$ & 98 & 2 & 1 & 0 & 1 \\
\hline 4. Conducting lineups & $86^{*}$ & 84 & 9 & 9 & 5 & 8 \\
\hline 5. Effects of post-event & $97 *$ & 94 & 1 & 6 & 2 & 0 \\
\hline \multicolumn{7}{|l|}{ information } \\
\hline \multirow[t]{2}{*}{ 6. Confidence/accuracy } & 2 & 22 & 20 & 48 & $78^{*}$ & 31 \\
\hline & \multicolumn{2}{|c|}{ Generally true $\%$} & \multicolumn{2}{|c|}{ Don’t know \% } & \multicolumn{2}{|c|}{ Generally false $\%$} \\
\hline 7. Confidence malleability & $92 *$ & 85 & 7 & 14 & 1 & 1 \\
\hline 8. Weapon focus & $52 *$ & 68 & 44 & 27 & 4 & 5 \\
\hline 9. Mugshot-induced bias & $84 *$ & 84 & 15 & 13 & 1 & 3 \\
\hline 10. Lineup presentation format & $22 *$ & 38 & 70 & 55 & 7 & 7 \\
\hline \multirow[t]{2}{*}{ 11. Forgetting curve } & $34 *$ & 51 & 40 & 25 & 27 & 24 \\
\hline & \multicolumn{2}{|c|}{ Agree $\%$} & \multicolumn{2}{|c|}{ Neither \% } & \multicolumn{2}{|c|}{ Disagree \% } \\
\hline 12. Impact of stress & $65^{*}$ & 70 & 26 & 19 & 9 & 11 \\
\hline 13. Attorneys' knowledge & 2 & 12 & 21 & 41 & $77^{*}$ & 47 \\
\hline 14. Jurors' knowledge & 1 & 3 & 14 & 24 & $85^{*}$ & 73 \\
\hline 15. Jurors distinguish & 0 & 8 & 38 & 52 & $62 *$ & 40 \\
\hline
\end{tabular}

Note. Correct answers are indicated by *. 
Table 3.

$\chi^{2}$ Tests Comparing Accuracy Scores for Each Eyewitness Knowledge Item in the 2008 and 2019

Samples.

\begin{tabular}{|c|c|c|c|c|c|c|}
\hline Topics & $\chi^{2}(1)$ & $p$ & $\operatorname{Adj} \cdot p$ & V & $\begin{array}{c}\text { Accuracy } \\
\% \\
2019\end{array}$ & $\begin{array}{c}\text { Accuracy } \\
\% \\
2008\end{array}$ \\
\hline \multicolumn{7}{|l|}{ Estimator variables } \\
\hline Effects of a hat $* * *$ & 13.61 & $<.001$ & .001 & 0.23 & 31 & 55 \\
\hline Minor details* & 6.09 & .01 & .03 & 0.15 & 47 & 31 \\
\hline Attitudes and expectations & 0 & 1 & 1 & 0 & 98 & 98 \\
\hline Forgetting curve* & 6.62 & .01 & .03 & 0.16 & 34 & 51 \\
\hline Weapon focus* & 5.98 & .01 & .03 & 0.15 & 52 & 68 \\
\hline Impact of stress & 0.43 & .51 & .64 & 0.04 & 65 & 70 \\
\hline \multicolumn{7}{|l|}{ System variables } \\
\hline Conducting lineups & 0.16 & .69 & .80 & 0.02 & 86 & 84 \\
\hline Effects of post-event information & 0.46 & .50 & .64 & 0.04 & 97 & 94 \\
\hline Confidence/accuracy*** & 51.15 & $<.001$ & $<.001$ & 0.45 & 78 & 31 \\
\hline Confidence malleability & 2.18 & .14 & .21 & 0.09 & 92 & 85 \\
\hline Mugshot-induced bias & 0 & 1 & 1 & 0 & 84 & 84 \\
\hline Lineup presentation format* & 6.17 & .01 & .03 & 0.16 & 22 & 38 \\
\hline \multicolumn{7}{|l|}{ Jurors' and attorneys' knowledge } \\
\hline Attorneys' knowledge $* * *$ & 20.27 & $<.001$ & $<.001$ & 0.28 & 77 & 47 \\
\hline Jurors' knowledge* & 4.24 & .04 & .07 & 0.13 & 85 & 73 \\
\hline Jurors distinguish & 11.24 & $<.001$ & .003 & 0.21 & 62 & 40 \\
\hline eyewitnesses $* * *$ & & & & & & \\
\hline
\end{tabular}

Note. V $=$ Cramer's $V ;{ }^{*} p<.05 ; * * p<.01 ; * * * p<.001 ;$ Adj. $p=$ Adjusted $p$-values using the Benjamini-Hochberg False Discovery Rate. 


\section{Figures}

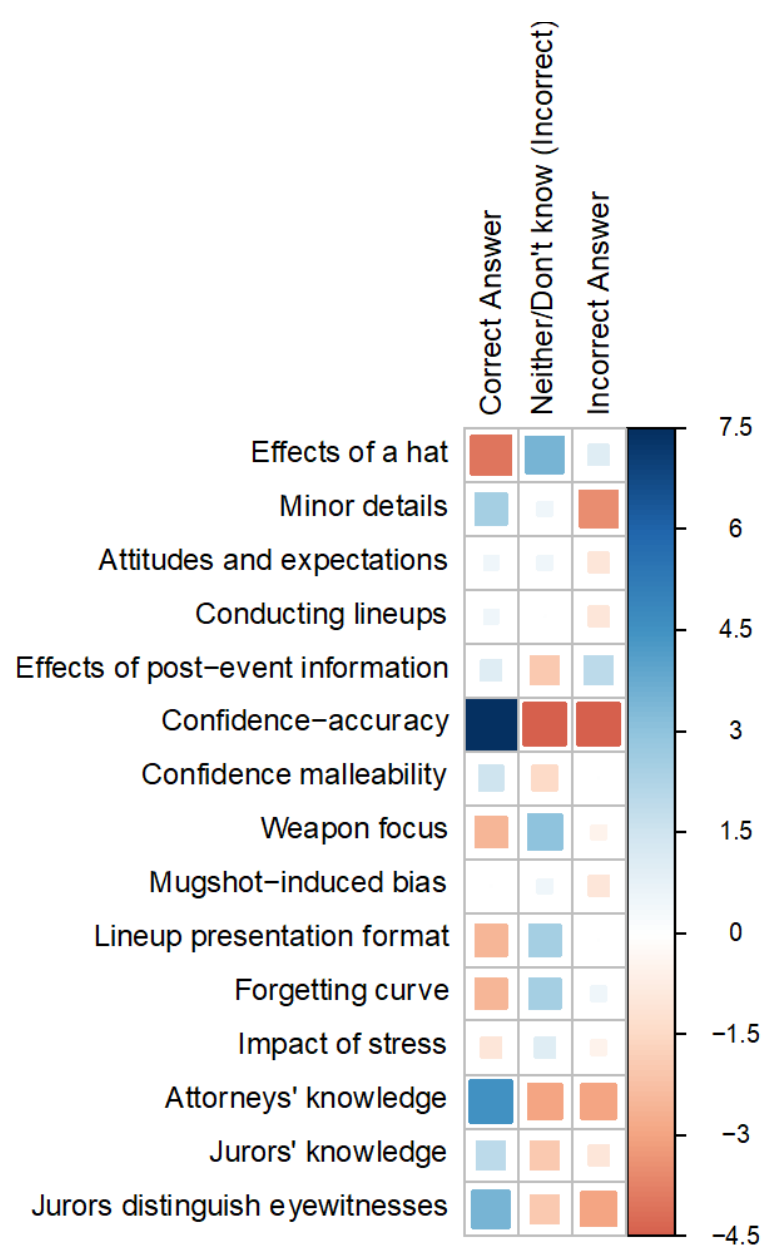

Figure 1. Distribution of residuals from the Pearson's $\chi^{2}$ tests comparing judges' responses in 2019 and 2008. Positive residuals (in blue) represent an increase in the proportion of judges that chose a particular response alternative, and negative residuals (in red) represent a decrease. The colour bar shows the span of residuals (-4.5 to 7.5). The left-hand column shows improvements (blue) and declines (red) in overall accuracy. The middle column shows changes in how frequently the 'neither' or 'don't know' options were chosen. The right-hand column shows increases and decreases in the proportion of judges choosing incorrect answers. 


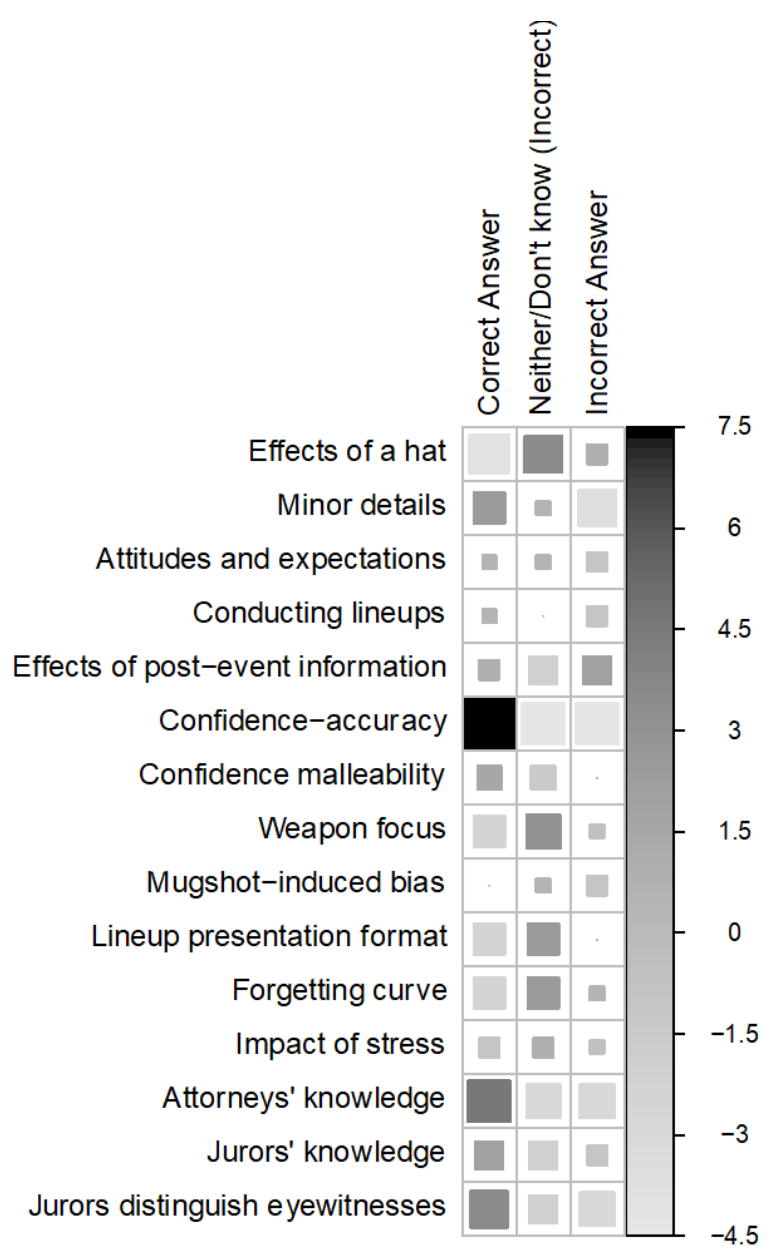

Figure 1. Distribution of residuals from the Pearson's $\chi^{2}$ tests comparing judges' responses in 2019 and 2008. Positive residuals (dark grey and black) represent an increase in the proportion of judges that chose a particular response alternative, and negative residuals (light grey and white) represent a decrease. The colour bar shows the span of residuals (-4.5 to 7.5). The left-hand column shows improvements (dark grey and black) and declines (light grey and white) in overall accuracy. The middle column shows changes in how frequently the 'neither' or 'don't know' options were chosen. The right-hand column shows increases and decreases in the proportion of judges choosing incorrect answers. 